\title{
ESTRATÉGIAS DISCURSIVAS PARA UM ETHOS DE CREDIBILIDADE NO DEBATE POLÍTICO
}

\author{
Wagner Alexandre dos Santos Costa \\ Universidade Federal Rural do Rio de Janeiro \\ Instituto de Ciências Humanas e Sociais \\ Departamento de Letras e Comunicação \\ Seropédica, RJ, Brasil
}

\begin{abstract}
Resumo: A cena política depende da relação entre identidade social e identidade discursiva. Em diversas situações de sua atividade, o político deve construir um ethos de credibilidade, uma vez que está sempre envolvido em uma luta discursiva. Neste artigo, faz-se uma análise qualitativa da construção da imagem favorável de si por meio de estratégias discursivas como justificação, dissimulação e promessa - em debate político televisivo das eleições de 2016 ao cargo de Prefeito da Cidade do Rio de Janeiro. A hipótese confirmada é de que os políticos líderes nas pesquisas de opinião precisassem articular mais intensamente essas estratégias, sobretudo a da justificação. Além disso, os dados levaram à identificação de mais uma estratégia discursiva (congraçamento), e a análise à conclusão de que os candidatos constroem espaços de acordo somente apreensíveis por uma observação atenta. O aporte teórico do estudo é a Teoria Semiolinguística de Charaudeau (2006a, 2006b, 2010, 2011, 2016).
\end{abstract}

Palavras-chave: Discurso político. Ethos discursivo. Debate televisivo.

\section{INTRODUÇÃO}

Neste artigo, empreendemos um estudo acerca da elaboração do ethos de credibilidade no cenário do debate político de TV. Partimos da indagação de como os discursos da justificação, da promessa e da dissimulação engendravam a formulação de uma imagem favorável de si na fala dos candidatos ao cargo de prefeito da Cidade do Rio de Janeiro nas eleições de 2016.

A situação de comunicação, face a face com o adversário, ao vivo e, sobretudo, às vésperas das eleições - o que representava uma última oportunidade de fala para um grande número de espectadores -, exigia que os políticos mobilizassem estratégias eficientes para construir/manter sua imagem de político habilitado emocional, moral e intelectualmente.

Nossa hipótese era a de que os candidatos líderes nas pesquisas de opinião necessitavam com mais veemência arrolar estratégias para defesa de si, sobretudo a de justificação, o que em parte se atestou nos resultados. Além disso, demonstrou-se que os políticos adotavam uma estratégia ainda não descrita por Charaudeau (2006a, 2011, 2016): o discurso do congraçamento.

\footnotetext{
* Doutor em Estudos da Linguagem pela Universidade Federal Fluminense (UFF) e Professor Adjunto na Universidade Federal Rural do Rio de Janeiro (UFRRJ). Pesquisador do grupo Estudos Linguísticos, Multiletramentos e Ensino de português (ELMEP/UFRRJ).E-mail: wagnerasc@ bol.com.br.
} 
Em nossas conclusões, destacamos ser o discurso do congraçamento, aliado ao discurso da promessa, uma estratégia compósita que atendia a um tipo de acordo entre determinados candidatos para driblar a dificuldade de exposição das suas propostas de governo e consequente também difícil formulação de uma imagem credível de si.

Os dados coletados das falas dos candidatos no curso do debate consistem em transcrições literais de suas falas. A coleta se restringiu aos tipos de discurso aqui elencados, e sua forma de tratamento foi qualitativa. Na plataforma YouTube ${ }^{1}$ encontramse os vídeos do debate, que aconteceu no dia 29/09/2016 nos estúdios da TV Globo, no Rio de Janeiro.

O aporte teórico principal a que se vincula o estudo é a Teoria Semiolinguística (CHARAUDEAU, 2006a, 2006b, 2011, 2016). Ainda, o estudo está amparado em contribuições sobre a noção de ethos discursivo, tal como tratada em Maingueneau (2005, 2011), Amossy (2005) e Charaudeau (2011, 2016).

O artigo está organizado da seguinte maneira: a seção seguinte, de número 2 , traz o aporte teórico que embasa o estudo. Em seguida, tem-se a seção 3, que descreve o aparato metodológico empregado e a análise dos dados. Por fim, seguem-se a conclusão, seção 4 , e as referências.

\section{APORTE TEÓRICO}

\subsection{NOTAS SOBRE O CONCEITO DE ETHOS DISCURSIVO}

A noção de ethos é atualmente compreendida por variados prismas teóricos. O ethos discursivo, a seu turno, tem sido compreendido de maneira semelhante por diferentes autores. De acordo com Perelman e Olbrechts-Tyteca (1999), ethos resume-se à impressão que o orador, por suas palavras, constrói intencionalmente de si mesmo no processo da argumentação. De maneira semelhante, embora moldado pelo quadro teórico da Análise do Discurso, no interior do qual o conceito se vincula à adesão dos sujeitos por meio do discurso, Maingueneau (2011, p. 97) entende-o pelo fenômeno em que "por meio da enunciação, revela-se a personalidade do enunciador", e Amossy (apud MAINGUENEAU; CHARAUDEAU, 2004, p. 220) considera-o "a imagem de si que o locutor constrói em seu discurso para exercer uma influência sobre seu alocutário".

Assim, o conceito não envolve propriamente as coisas que o orador poderia dizer sobre si, visto que estas informações diriam respeito ao sujeito real, encarnado, situado no espaço social, e não ao sujeito da enunciação, a pessoa como ser que fala, inscrita no ato de comunicação. Esta categoria se refere, por exemplo, à sua maneira de estruturar as frases, à sua seleção vocabular, a seus conhecimentos enciclopédicos demonstrados no discurso e ao seu estilo, que podem fornecer informações sobre sua pessoa, podem "falar" por ele. O ethos se situa, então, na aparência do ato de linguagem:

\footnotetext{
${ }^{1} \mathrm{O}$ endereço da plataforma é <https://www.youtube.com/?gl=BR\&hl=pt>. Os links de acesso aos vídeos serão disponibilizados na seção 3.1 .
} 
Falar é, ao mesmo tempo, falar ao outro, falar de si e falar do mundo. Mais exatamente, é falar de si através do outro, ao falar do mundo. Não há, pois, ato de linguagem que não passe pela construção de uma imagem de si. Desde o instante em que se fala, aparece, transparece, emerge de si, uma parte do que se é através do que se diz. (CHARAUDEAU, 2016, p. 72)

Esta instância subjetiva que se manifesta como "voz" e como "corpo enunciante", como sublinha Maingueneau (2005, p. 70), pode ser recuperada a partir de indícios textuais variados que formam o ethos.

Os antigos já se dedicavam ao estudo do ethos. Eggs (2005, p. 32) e Charaudeau (2011, p. 113), retomando Aristóteles, lembram que os oradores inspiram confiança conforme apresentem três tipos de qualidade em seus argumentos: (a) sabedoria e razoabilidade (a phronésis), (b) honestidade e sinceridade (a arétê), e (c) solidariedade e amabilidade (a eunóia).

Em Retórica, Aristóteles (2005, p. 96), ao explicar que as provas de persuasão fornecidas pelo discurso são de três tipos, apresenta aquelas que residem no caráter moral do orador (ethos), outras que dependem do modo como se dispõe o ouvinte (pathos) e as que se situam no próprio discurso (logos).

Segundo ele, o caráter é o meio mais importante de persuasão:

Persuade-se pelo caráter quando o discurso é proferido de tal maneira que deixa a impressão de o orador ser digno de fé. Pois acreditamos mais e bem mais depressa em pessoas honestas, em todas as coisas em geral, mas sobretudo nas de que não há conhecimento exato e que deixam margem para dúvida. (ARISTÓTELES, 2005, p. 96)

Mas, advertia o autor que tal confiança deveria decorrer de um efeito do discurso, não de um juízo prévio.

Para obter esse ideal de persuasão, o sujeito falante precisa tomar conhecimento das ideias e dos valores do destinatário. Somente assim poderá eleger a maneira mais apropriada de se expressar, condizente com seu projeto de fala. Dessa forma, o ethos corresponderá à imagem necessária ao locutor para conquistar credibilidade junto ao seu interlocutor.

Assim, segundo Maingueneau (2005), privilegiando a visão aristotélica, a eficácia do ethos deve-se ao fato de que, sem estar explicitado no enunciado, ele envolve de alguma forma a enunciação. Trata-se da escolha das palavras, dos argumentos, do ritmo e da entonação de seu discurso.

Com efeito, segundo Maingueneau (2005), este conceito abarca, além da vocalidade, também as características físicas e psicológicas atribuídas ao enunciador a partir de representações coletivas, as quais participam de um conhecimento compartilhado. Ressalte-se, entretanto, que o enfoque dado por ele não recai sobre a dimensão sociológica em que se situa o sujeito (inserido em um dado grupo social, em um tipo físico e em determinada ideologia), em detrimento da linguagem, tal como o faz Bourdieu ao dizer que "A linguagem no máximo representa essa autoridade. Ela a manifesta, ela a simboliza." (1982, p. 105, apud AMOSSY, 2005, p. 138). 
Charaudeau (2011), por sua vez, ao abordar a problemática de o ethos ser resultado de uma construção discursiva (ethos construído) ou decorrer de uma instância prévia ao discurso (ethos pré-construído), argumenta em favor de uma visão intermediária. Segundo ele, para construir uma imagem do sujeito que fala, o interlocutor se apoia em dados apreendidos no fio do discurso, mas também se utiliza de informações sobre a pessoa, não só sobre sua configuração como enunciador:

\begin{abstract}
De fato, o ethos, enquanto imagem que se liga àquele que fala, não é uma propriedade exclusiva dele; ele é antes de tudo a imagem de que se transveste o interlocutor a partir daquilo que diz. O ethos relaciona-se ao cruzamento de olhares: olhar do outro sobre aquele que fala, olhar daquele que fala sobre a maneira como ele pensa que o outro o vê. Ora, para construir a imagem do sujeito que fala, esse outro se apoia ao mesmo tempo nos dados preexistentes ao discurso - o que ele sabe a priori do locutor - e nos dados trazidos pelo próprio ato de linguagem (CHARAUDEAU, 2011, p. 115).
\end{abstract}

O ethos, como recurso linguageiro de que o sujeito se utiliza no uso da palavra para convencer seu destinatário, possui duas dimensões: uma vinculada à identidade social do locutor, que lhe dá direito à palavra; outra, a sua identidade discursiva, projetada em função do papel discursivo desempenhado e da consequente estratégia que pretende adotar.

Então, de acordo com a abordagem de Charaudeau, complementar à aristotélica, o ethos (prévio ou discursivo) é uma identidade independente que está vinculada a duas outras: a identidade social (lugar de legitimidade) e a identidade discursiva (lugar de credibilidade), ambas desenvolvidas no escopo da Teoria Semiolinguística (CHARAUDEAU, 2010).

\title{
2.2 ETHOS E ESTRATÉGIAS DISCURSIVAS NO CAMPO POLÍTICO 2.2.1 IDENTIDADE SOCIAL E IDENTIDADE DISCURSIVA
}

Charaudeau (2006a, p. 344) particulariza a identidade social pela necessidade de ser reconhecida pelos outros. Trata-se, nos termos dessa teoria, daquilo que confere ao sujeito o direito à palavra, o que sustenta a sua legitimidade, que depende da atuação do sujeito nos domínios do saber (fundado nas opiniões, nos saberes compartilhados e no seu manuseio, com vistas à sedução e persuasão do interlocutor) e do poder (estabelecido principalmente a partir dos vínculos institucionais que conferem poder ao sujeito).

A identidade discursiva, sem se opor à anterior, apenas projetando-se num contínuo, depende não somente de o sujeito saber organizar sua fala, mas principalmente de sua capacidade em parecer digno de crédito, da necessidade de seu interlocutor considerá-lo verdadeiro. Por essa razão, a credibilidade, que depende da identidade discursiva, envolve a formulação de uma imagem de si, um ethos, sendo, pois, necessariamente estratégica.

Trata-se de uma interdependência de dois espaços reguladores do ato de comunicação: um contendo determinações sociais, outro discursivas, sendo o ethos realizado sociodiscursivamente. Assim esquematizamos: 


\section{Figura 1 - 0 social e o discursivo na formulação do ethos}

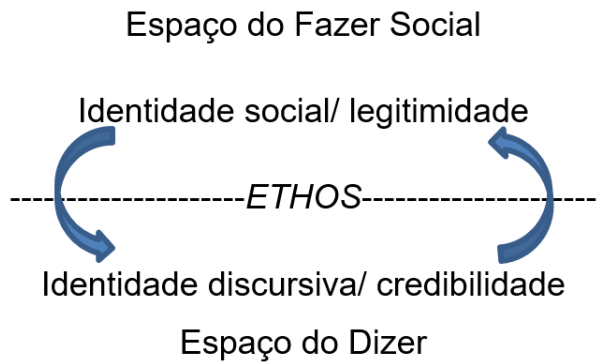

Quanto ao domínio político, Charaudeau (2016, p. 73) explica que legitimidade e credibilidade estão intimamente entrelaçadas. A legitimidade conferida a um candidato pelo voto não é absoluta nem definitiva. É, pois, necessária a manutenção constante dela. Isto passa pelo exercício da credibilidade, que se faz pela linguagem.

\subsubsection{Estratégias discursivas na encenação política}

Concebendo a atuação do político como fruto da relação entre a identidade social e a identidade discursiva, Charaudeau (2006b, p. 257) ressalta dois tipos de atividades determinantes:

- a do dizer político, do debate de ideias no vasto campo do espaço público, lugar onde se trocam opiniões;

- a do fazer político, no campo mais restrito do espaço onde se tomam decisões e se realizam atos.

O sujeito político, assim, tem de construir sua palavra na interseção desses dois espaços porque seu dizer (linguagem) deve, em tese, ser autenticado por seu fazer (ação), por sua atuação, ou se circunscreverá apenas nos limites da promessa. Esses dois espaços, por um lado, são recíprocos e complementares, mas por outro, são diferentes:

\footnotetext{
- no primeiro (dizer), é a linguagem que domina, através de uma luta discursiva em que várias estratégias são permitidas (manipulação, proselitismo, ameaças / promessas, etc.), o objetivo sendo a imposição de uma opinião;

- no segundo (fazer), é a ação como o espaço onde se exerce o poder de agir entre uma instância política que se diz soberana e uma instância cidadã que, a todo momento, pode pedir contas e resultados, o objetivo sendo uma dominação feita de regulamentação, de sanção e de reivindicação. (CHARAUDEAU, 2006b, p. 257-258).
}

Diferentes porque se pautam em dois tipos de forças: força de verdade e força de ação, e complementares uma vez que, por outro lado, cruzam-se em linguagem-ação, base para qualquer atividade discursiva política, seja na governança, seja na oposição. 
A atividade política, por envolver uma constante tensão entre o controle do poder e a oposição por quem não o exerce, determina estratégias discursivas distintas. Como pontua Charaudeau (2006b, p. 258), o sujeito político pode estar em uma situação de enunciação fora da governança, quando, por exemplo, pretende conquistar um cargo político, quando disputa eleições. Pode ainda enunciar de dentro dela, caso em que ocupa algum cargo.

Por serem distintas também as condições de legitimidade desses sujeitos, em função delas deverão adotar estratégias discursivas adequadas, sobretudo em condições de embate e luta pela conquista ou manutenção do poder, como ilustra a situação de campanha eleitoral que prevê debates públicos ao vivo na TV.

Assim, diversos tipos de estratégias discursivas podem ser postas em cena no campo político: a da promessa, a de decisão, a de justificação e a de dissimulação, segundo lista Charaudeau (2006b, p. 258-261).

Na estratégia da promessa o político deve, simultaneamente, ser capaz de a) contemplar um ideal social de desejo/necessidade do ouvinte, mas também adequar-se às possibilidades reais de sua execução; b) obter reconhecimento, da parte dos cidadãos, como merecedor de crédito, como portador de limpas intenções e c) conseguir convencer (uso da razão) e persuadir (uso da emoção) a maioria da instância cidadã.

Em relação à tensão entre o domínio do poder e a oposição, no primeiro acentua-se a necessidade de articulação justa entre força de verdade e força de ação, haja vista que o sujeito político encontra-se sob os olhares de seus oponentes e também da população. $\mathrm{O}$ segundo, por não ocupar cargo, não estará sendo avaliado pelo que pode/pôde fazer.

A estratégia de decisão, a seu turno, está legitimada no campo da ação e possível ao político que pode executá-la. Identifica-se uma desordem social, enuncia-se o dever de sua correção e revela-se a solução (a ser) adotada.

Já a estratégia de justificação (CHARAUDEAU, 2006b, 2011) decorre da necessidade de os atores políticos se defenderem das críticas de seus opositores e da sociedade ou, às vezes, de antecipar-se a elas. As ações dos sujeitos políticos podem afetar sua legitimidade, sendo necessário recorrer a estratégias discursivas de (re)legitimação do estatuto conquistado. Essa tensão será constante, devendo não só ao político no controle da governança, mas ainda mesmo após o término do seu mandato, haja vista que suas ações compõem um histórico de sua vida política pregressa.

Por fim, a estratégia de dissimulação pode ser compreendida como o esforço em reduzir, pelo silêncio, a relevância de ideias que se projetam desfavoravelmente em direção ao ator político. A dissimulação é, então, uma estratégia discursiva de reação contra efeitos negativos emanados pela oposição, pela mídia ou por movimentos sociais.

Tendo, então, delimitado o aporte teórico que sustenta nosso estudo, passamos, na próxima seção, à metodologia e análise dos dados. 


\section{EM CENA O DEBATE: AS ESTRATÉGIAS DISCURSIVAS NA CONSTRUÇÃO DO “ETHOS DE CREDIBILIDADE”}

Inicialmente, trataremos da metodologia empregada na pesquisa, apresentando o contexto do debate político, os procedimentos de coleta de dados e de análise, a justificativa e, por fim, os objetivos e as hipóteses norteadores do trabalho. Em seguida, analisaremos os dados à luz do suporte teórico.

\subsection{METODOLOGIA}

O presente estudo trata do desempenho discursivo, em debate televisivo transmitido ao vivo, de oito políticos que disputavam o cargo de prefeito da Cidade do Rio de Janeiro nas eleições de 2016. O debate ocorreu no dia 29/09/2016 e foi organizado pela TV Globo, que convidou alguns desses candidatos, informando seus critérios:

a) estar filiado a uma organização política com representação superior a nove parlamentares na câmara dos deputados; e

b) ter alcançado um mínimo de $5 \%$ de intenção de votos na pesquisa realizada pelo instituto Datafolha, em 5/09/2016.

Participaram do debate, conforme o recorte, os seguintes candidatos: Jandira Feghali (PC do B), Pedro Paulo (PMDB), Flávio Bolsonaro (PSC), Índio da Costa (PSD), Carlos Osório (PSDB), Marcelo Crivella (PRB), Marcelo Freixo (PSOL) e Alessandro Molon (REDE). Ficaram excluídos três concorrentes: Cyro Garcia (PSTU), Carmen Migueles (NOVO) e Thelma Bastos (PCO).

O evento foi mediado pela jornalista Ana Paula Araújo e está disponível na plataforma YouTube para livre acesso em:

- <https://www.youtube.com/watch?v=sIeQjs5nRYM> (referente ao bloco 1, em que a formulação da pergunta e o seu candidato alvo eram de livre escolha),

- <https://www.youtube.com/watch?v=9PFZAupZ4ss > (referente ao bloco 2, em que a formulação da pergunta foi determinada por sorteio e seu alvo ainda de livre escolha),

- <https://www.youtube.com/watch?v=9jL9I0FrYfk> (referente ao bloco 3, que obedeceu às mesmas regras do primeiro) e

- <https://www.youtube.com/watch?v=hG1ORMt0rio> (referente ao bloco 4, que trouxe as considerações finais dos candidatos).

Todos os links foram acessados de dezembro/2016 a março/2017 e a coleta foi orientada pela classificação das estratégias discursivas políticas envolvidas na construção da credibilidade em contexto de pergunta/resposta. Foram, assim, selecionadas nos blocos 1,2 e 3 falas que se enquadrassem nas categorias justificação, promessa, dissimulação ou decisão (CHARAUDEAU, 2011, 2016), já o bloco 4 foi desprezado por conter falas fora do contexto de nosso interesse. 
O estudo assume caráter qualitativo, prevalecendo a interpretação como forma de análise dos dados. Dessa forma, em cada turno de fala, não coletamos ocorrências repetidas da mesma estratégia, observando somente se tal ou qual estratégia esteve presente no turno de fala do candidato e se ele empregou mais de uma delas.

O trabalho se justifica pela importância do desempenho discursivo dos candidatos nesse debate, que representou a última oportunidade de defesa das candidaturas em um espaço privilegiado de audiência e, sobretudo, face a face com os oponentes. Este detalhe significava para o político não poder construir, sem intervenção do concorrente, sua imagem de candidato honesto, amável e eficiente, qualidades fundamentais na conquista dos eleitores. Além disso, o evento discursivo que motivou o estudo possibilita ampliar a reflexão proposta na formulação teórica feita por Charaudeau no que respeita às relações entre poder, estratégia discursiva e ethos político $(2011,2016)$.

Posto isto, o objetivo geral deste estudo é analisar a construção de um ethos de credibilidade para a conquista/manipulação da opinião pública por meio de estratégias discursivas de justificação, promessa, dissimulação, decisão e congraçamento. Assim, indagamos: qual é o papel das referidas estratégias na edificação/manutenção desse ethos no debate eleitoral? Especificamente, objetivamos mapear o quadro de ocorrência de tais estratégias, observar as relações entre elas e compreender a sua importância na defesa de si em face do adversário e diante do público.

Nossa hipótese principal foi a de que Pedro Paulo e Crivella eram os políticos que necessitavam articular com mais intensidade as estratégias de justificação. Aquele por representar a legenda do poder, este por liderar as intenções de voto.

Por fim, feitas as considerações metodológicas, passamos, na próxima seção, à análise dos dados coletados no debate.

\subsection{ANÁLISE DOS DADOS}

\subsubsection{O DISCURSO DA JUSTIFICAÇÃO}

No bloco 1, a candidata Jandira Feghali, única mulher entre os oito candidatos, inicia sua fala em direção à atuação política pregressa de Pedro Paulo. Jandira afirma que o candidato apoiou o impeachment da presidenta Dilma Rousseff, que fora eleita com 54 milhões de votos. Segundo a candidata, isto configurou o que chamou de "golpe" e, em sua visão, Pedro Paulo teria participado dele, de modo que os 54 milhões de votos teriam sido desrespeitados e desperdiçados. Além disso, ela afirma que Pedro Paulo seria "agressor de mulheres". Jandira, então, apresenta dois questionamentos: no primeiro, ela põe em dúvida a coerência de Pedro Paulo em pedir votos, já que ele teria desperdiçado todos os 54 milhões de Dilma. Em seguida, duvida também de sua capacidade para gerir uma cidade com maioria de mulheres como é o Rio de Janeiro, por estar envolvido em um escândalo de agressão à sua ex-mulher: "Você é um agressor de mulheres", disse ela.

Pedro Paulo nega a suposta agressão à sua ex-mulher, dizendo ter sido inocentado pela justiça. Note-se que ele, sendo o candidato do PMDB, representava o poder e a possibilidade de sua continuação, já que o prefeito Eduardo Paes pertencia ao mesmo partido. 
O candidato, em contrapartida, inverte o jogo de acusações e afirma que Jandira, sim, é que estaria envolvida em casos que desmereciam sua candidatura. Ele afirma que sua adversária teria recebido propina e seria alvo de investigações pelo Ministério Público. Vejam-se as respostas de cada um, literalmente transcritas:

(1)

JANDIRA FEGHALI: "Além de agressor de mulheres, você mente. Eu jamais fui acusada de receber propina, o que foi dito é que o PC do B recebeu recursos de uma empresa. E doação legal não é crime. E a minha resposta a você é o meu imposto de renda".

PEDRO PAULO: "Essas acusações que você está fazendo são falsas e eu fui inocentado".

Uma vez que sua imagem de honestidade, amabilidade e eficiência estava sendo ameaçada, restava a Pedro Paulo negar a acusação e atribuí-la ao caráter de má-fé de sua oponente. Ambos adotam a estratégia da justificação contra uma investida na base de suas imagens de credibilidade política e/ou moral, como se vê na fala de Jandira Feghali, ao negar a acusação de Pedro Paulo e explicar, segundo ela, o que acontecera de fato.

A palavra de justificativa, conforme afirma Charaudeau (2016, p. 20), é aquela inerente à vida política no espaço do poder. Assim, Pedro Paulo, por representar a legenda detentora do mandato passa a ser um dos principais alvos das críticas daqueles que se situam no contrapoder, o que exigiu como recurso necessário a defesa pela justificação das ações governamentais de seu partido e pessoais suas. Jandira, por outro lado, em decorrência de ter realizado ataques tão incisivos, teve de se defender do "você também" aplicado por Pedro Paulo no contra-ataque.

Ainda no bloco 1, a seguir, Pedro Paulo dirige sua fala ao candidato Marcelo Crivella, perguntando sobre a proposta deste para a área da segurança. Crivella não responde objetivamente à pergunta feita por Pedro Paulo; desvia do tema proposto, criticando a campanha do adversário, em uma tentativa de descredibilizá-lo. Ele desconsidera o tema da pergunta e instaura o seu próprio, desenvolvendo uma sequência de justificativas que objetivavam dissociar seu futuro mandato dos dogmas defendidos pela Igreja Universal, onde atuava religiosamente.

A estratégia mais evidente é a da justificativa por desenvolver argumentos que tentavam afastar a dúvida sobre sua legitimidade para assumir o cargo de prefeito, uma vez que o seu vínculo religioso poderia ferir o princípio da laicidade do Estado, se os limites entre política e religião não fossem adequadamente estabelecidos. No entanto, predominou nesta passagem a estratégia discursiva da dissimulação, por Crivella simplesmente não ter sido cooperativo com o que foi tematicamente proposto por Pedro Paulo, por desviar da pergunta, não respondê-la e ainda reformular o tópico à maneira que lhe foi conveniente. Esta estratégia (dissimulação) será retomada logo adiante, porém vejamos outro caso de justificação:

(2)

MARCELO FREIXO: "Antes eu queria só esclarecer que em 2012 teve uma empresa sim que doou para a minha campanha e para um vereador do PSOL. Na época, nenhuma irregularidade, isto está lá constatado. Foi a mesma empresa que depois em 2014 e 2015 Pedro Paulo e Eduardo Paes usaram para demolir a Vila Autódromo. A diferença entre a gente é que eu estava do lado dos moradores da Vila Autódromo, vocês estavam do lado da especulação imobiliária defendendo aquela covarde remoção". 
Em (2), em dado coletado do bloco 3, Marcelo Freixo é levado a adotar a justificação para se defender da acusação feita anteriormente por Pedro Paulo. Este acusou Freixo de receber doação de empresa, mas negar envolvimento com a empreiteira. Freixo, então, retoma o fato pregresso e tenta explicar que a doação foi regular e, ainda, que a empreiteira em questão à época da doação não estaria envolvida em problemas. A negação é um dos recursos da justificação. O político reivindica a legitimidade do seu ato e discorda da acusação (CHARAUDEAU, 2011, p. 127).

Por Pedro Paulo ter sido intensamente atacado no debate, adotou o recurso do contra-ataque, expondo também falhas dos seus debatedores. A decorrência foi impor a eles adotar a estratégia da justificação, com exceção de Crivella, que desviava da pergunta ou da acusação, empregando a estratégia da dissimulação, como no exemplo da próxima seção, extraído do bloco 2.

\subsubsection{O DISCURSO DA DISSIMULAÇÃO}

Nesta ocorrência, em que Pedro Paulo pergunta a Crivella qual seria sua proposta para a segurança, uma pergunta que incidiria sobre seu programa de governo, Crivella novamente ignora o que lhe foi proposto e conduz a resposta segundo sua estratégia de pontuar críticas ao PMDB e, por extensão, ao oponente. A dissimulação é sinalizada pelo oponente, que chama a atenção para Crivella não ter respondido mais uma vez a pergunta apresentada.

(3)

MARCELO CRIVELLA: “[...] não posso deixar de citar que o pior problema para a nossa cidade é a falta de respeitabilidade dos nossos políticos. Recentemente, quando se foi fazer uma entrega de uma casa a uma senhora pobre, se inventou uma história de "canguru-perneta $[\ldots] "$.

PEDRO PAULO: "Bispo Crivella, mais uma vez você não respondeu a pergunta".

Ainda, na sequência de embates, Crivella adota a mesma estratégia ao ser questionado por Pedro Paulo se o ex-governador Garotinho seria seu secretário de segurança:

(4)

MARCELO CRIVELLA: "O povo do Rio está é preocupado em saber se o Eduardo Cunha vai ser seu secretário de fazenda. Você pediu licença duas vezes para votar a favor dele, vocês estão envolvidos no Lava-jato, no Petrolão [...]".

Nesse trecho, vê-se com mais clareza a opção de Crivella pelo discurso da dissimulação como estratégia de enfraquecer a fala do seu opositor pelo desprezo a ela conferido. Por outro lado, fica a dúvida se tal estratégia não seria meio de se esquivar da resposta, que não teria ou que não poderia oferecer de modo convincente e favorável a seu ethos de credibilidade. Já a estratégia a seguir, o discurso da promessa, obteve bastante expressividade na fala da maioria dos candidatos. 


\subsubsection{O DISCURSO DA PROMESSA}

A construção do ethos de credibilidade não podia ser levada a cabo livremente pelos políticos sem o risco da interferência das acusações que se imputavam mutuamente ou sem a refutação recíproca das suas ideias. Deste fato decorre a tensão e o risco promovidos pelo debate político ao vivo, diferente das situações em que o político pode construir livremente sua autoimagem.

Todos os candidatos que representavam o contrapoder, motivados pela intencionalidade inerente à disputa, elaboram, dessa forma, críticas à administração de Eduardo Paes (PMDB). Os tópicos propostos por eles discutem problemas pontuais vivenciados pela cidade e, por hipótese, mal geridos pelo prefeito. Por extensão, configuram-se como críticas à candidatura de Pedro Paulo, já que este era um concorrente com chances, pois detinha um amplo serviço publicitário a seu favor e poderia disputar o segundo turno com Crivella.

Os dados coletados trazem mostras de situações em que os políticos adotam estratégia diversa do início do bloco 1 . Em vez de um embate com críticas frontais ao programa de governo do oponente e ao seu percurso na atuação política, vê-se que o candidato seleciona outro que não o ameaça diretamente, seja por não disputar pontos percentuais equilibradamente, seja pelo fato de o outro não ser aquele que lidera as intenções ou que representa o poder. Consegue-se, com esse expediente, espaço compartilhado para a apresentação de suas propostas, haja vista que não seria interessante desequilibrar a campanha de um adversário com já baixa intenção de votos. A meta principal daqueles que estavam em posições menos confortáveis era combater o oponente na posição almejada: Marcelo Freixo e Pedro Paulo (candidatos na iminência de disputar o segundo turno com Crivella). Pedro Paulo, por deixar entrever certa fragilidade emocional e, além disso, representar a legenda no poder (PMDB), foi o alvo principal. Vejam-se alguns exemplos de discurso da promessa empreendidos pelos políticos:

(5)

CARLOS OSÓRIO: "Nós vamos priorizar os profissionais da educação. Enquanto não tivermos professores bem remunerados e bem pagos, nós não vamos avançar em escolas novas, porque o importante é educar, e não fazer programa bonito para a televisão."

(6)

FLÁVIO BOLSONARO: "Eu vou mudar o foco da guarda municipal, que hoje é muito mais voltado para a arrecadação, para multas, para combate aos camelôs, para que ela faça segurança preventiva da população. Eu vou investir sim no treinamento, na qualificação desses profissionais."

(7)

ÍNDIO DA COSTA: "Eu vou criar uma secretaria municipal de segurança e essa secretaria vai trabalhar com informação, inteligência e tecnologia para poder cuidar de você, cuidar da sua família, fazer integração com o governo do estado, com a polícia civil, polícia militar."

(8)

JANDIRA FEGHALI: “[...] nós temos que trabalhar contra a cultura do estupro, que é predominantemente feita sobre a mulher negra, nós temos que trabalhar a escola dentro da favela, uma escola que dê a possibilidade desse jovem, dessa criança, desde a creche, ter uma escola inclusiva, uma escola aberta 
Esses exemplos, especificamente os casos (5), (6) e (7), apresentam o que denominamos "indicadores de promessa", ou seja, o uso de palavras, locuções, expressões ou frases que introduzem o discurso da promessa política. Neles, temos as construções verbais "vamos priorizar", "vou mudar" e "vou criar", em que os verbos principais remetem a atitudes determinantes para a elaboração da imagem de si necessária ao político: ser racional, estar atento às necessidades do povo, ter iniciativa. Esta organização do discurso da promessa foi recorrente em todos os candidatos; no entanto, menos observada na candidata Jandira Feghali.

Diferentemente, em (8), Jandira dá ênfase à expressão da necessidade por meio de "ter que". Já em outras ocasiões, ela emprega "é preciso", enfatizando de modo mais acentuado do que observado nos demais candidatos um certo tom de afetividade no seu programa de governo.

Essa afetividade não ocorre à toa. Lembra Charaudeau (2016, p. 20) que a palavra política, dirigida a um público heterogêneo, adota procedimentos que se dirigem à razão do público e outros à sua emoção.

Como já dito, o discurso da promessa esteve vinculado, com poucas exceções, a tréguas entre os debatedores, ao abordarem um tema que raramente encontrava no oponente uma visão também oposta.

Nossa análise identificou outro tipo de estratégia discursiva não descrita por Charaudeau (2006b, 2011, 2016); no entanto, amplamente empregada neste debate e facilmente recuperável em contextos de outros debates políticos. Trata-se do discurso do congraçamento, que apresentaremos a seguir.

\subsubsection{O DISCURSO DO CONGRAÇAMENTO}

Esta estratégia consiste no uso do acordo, da conciliação, da confirmação das ideias alheias. Trata-se de uma estratégia discursiva em uma ambiência diversa da justificação, em que é feita uma crítica. No congraçamento, as ideias são consoantes, não opositoras.

O político, nessa estratégia, concorda com a afirmação do outro ou silencia diante dela (é bom lembrar o ditado popular que diz "quem cala consente"), caso em que silenciar não significa ignorar sub-repticiamente, mas admitir como verdadeira a fala interlocutora.

Uma das ocorrências mais emblemáticas do discurso do congraçamento, apesar de um pouco longa, aconteceu entre os debatedores Flávio Bolsonaro e Marcelo Crivella. Apresentamos, a seguir, a sua transcrição:

(9)

FLÁVIO BOLSONARO: A educação, sem dúvida alguma, é a chave para o desenvolvimento do nosso país e todos nós defendemos uma educação em tempo integral. Agora, eu tenho uma grande preocupação sobre o que é que estão ensinando para as nossas crianças dentro de sala de aula. Qual é a sua proposta para melhorar a qualidade do ensino na cidade do Rio de Janeiro?

MARCELO CRIVELLA: Eu quero que seja uma escola sem partido. Eu acho que a Unesco define bem o que é educação. Educação é você aprender a conhecer, a construir, a conviver 
e a ser. É isso que a escola tem que se preocupar. [...] É isso que a escola deve ensinar, sem partido, sem ideologias, uma escola com liberdade, onde as pessoas possam desenvolver seu talento e sejam bem assistidas, que tenha merenda escolar, professor esteja motivado, que tenha meritocracia, que alcance os índices do IDEB e que possa ser a escola que traga orgulho aos pais que frequentaram.

FLÁVIO BOLSONARO: Quero concordar com você, Crivella, os índices do IDEB, principalmente no segundo segmento do ensino fundamental, mostram que o conteúdo do que está sendo ensinado para as nossas crianças dentro de sala de aula está equivocado. Eu também defendo uma escola sem partido, porque eu entendo que tem que haver neutralidade dentro de sala de aula, os alunos tem que ter a sua liberdade de opinião respeitada, e não sendo ameaçados, constrangidos por alguns professores como está acontecendo hoje, querendo impor a sua preferência político-partidária aos alunos [...]”.

No bloco 3, o tema e o político alvo da pergunta eram de livre escolha, detalhe importante para o entendimento desta estratégia. Os dois políticos em questão, Flávio Bolsonaro e Marcelo Crivella, são conhecidos por defenderem pautas associadas à direita ultraconservadora. Ambos apoiam um movimento denominado "Escola sem partido", que prega a proibição de certos temas transversais na escola, como sexualidade e diversidade cultural, caros para uma política educacional de base progressista.

A opção de Flávio Bolsonaro por Marcelo Crivella, então, não foi inconsciente e aleatória, já que tal posicionamento é considerado polêmico e controverso, segundo a orientação subjetiva de tal ou qual candidato. Nesse sentido, a escolha por Alessandro Molon, Jandira Feghali ou Marcelo Freixo, por exemplo, levaria a abordagem a um confronto de posicionamentos acerca do tema. No entanto, não foi o que ocorreu entre os dois candidatos, que apresentaram vozes consoantes, uma a confirmar a outra.

O discurso de congraçamento é, assim, eficiente recurso para realizar acordos nas entrelinhas, sem publicá-los textualmente. Depende, dessa forma, do conjunto de interesses compartilhados e pode se materializar por meio de certos itens, que denominamos "indicadores de congraçamento". São indicadores linguísticos da presença desse discurso. Observam-se acima, na fala de Flávio Bolsonaro, vários exemplos empregados pelo político: "todos nós defendemos", "Quero concordar com você, Crivella" e "Eu também defendo".

Outros exemplos de indicadores foram ainda encontrados nas falas dos demais políticos (exceto na de Pedro Paulo):

- "obrigado pela pergunta",

- "agradeço a sua pergunta sobre x",

- "você tem toda razão, fulano",

- "É isso, sicrano",

- "Olha, eu concordo que",

- "todos nós acreditamos que",

- "é importante a pergunta", além de expressões gestuais de concordância, como o gesto de mover a cabeça verticalmente em acordo com o interlocutor.

Os indicadores linguísticos servem, em geral, para introduzir na fala o discurso do congraçamento, mas podem apenas confirmar a consonância, se, por exemplo, posicionados posteriormente. Outra maneira de realização dessa estratégia é por Ø (zero), ou seja, com ausência de marca, com silêncio e sem gestual algum. 
Na seção seguinte, os dados coletados no estudo serão apresentados em gráficos, de modo que se possa visualizar mais amplamente a dinâmica das estratégias discursivas observadas no debate entre os candidatos ao cargo de prefeito da cidade do Rio de janeiro.

\subsubsection{UMA VISÃO PANORÂMICA DAS ESTRATÉGIAS NO DEBATE}

Antes de empreender uma discussão de caráter geral sobre as estratégias, cabe salientar que a estratégia da decisão não foi um recurso observado no debate, uma vez que ela se circunscreve no campo do poder, interpretado como atuação já legitimada pelo voto. O político, diante do reconhecimento de uma ação necessária, enuncia a medida a ser tomada em relação a ela.

Os políticos deste debate não se situam estritamente nesse espaço; buscam essa legitimidade, não a têm. Pedro Paulo representa a legenda do poder, mas não o político já eleito para o poder. Acerca disso, diferentemente, quando pensamos a estratégia do discurso da justificação como recurso de formulação/manutenção de uma imagem política favorável de si, não a reduzimos apenas ao espaço do poder já legitimado pelo voto (no exercício), mas compreendemos como poder também as situações variantes em que se encontravam esses dois atores políticos.

Segue-se, então, o gráfico 1 com os tipos de estratégia e sua representação: ${ }^{2}$

\section{Gráfico 1 - Tipos de estratégia}

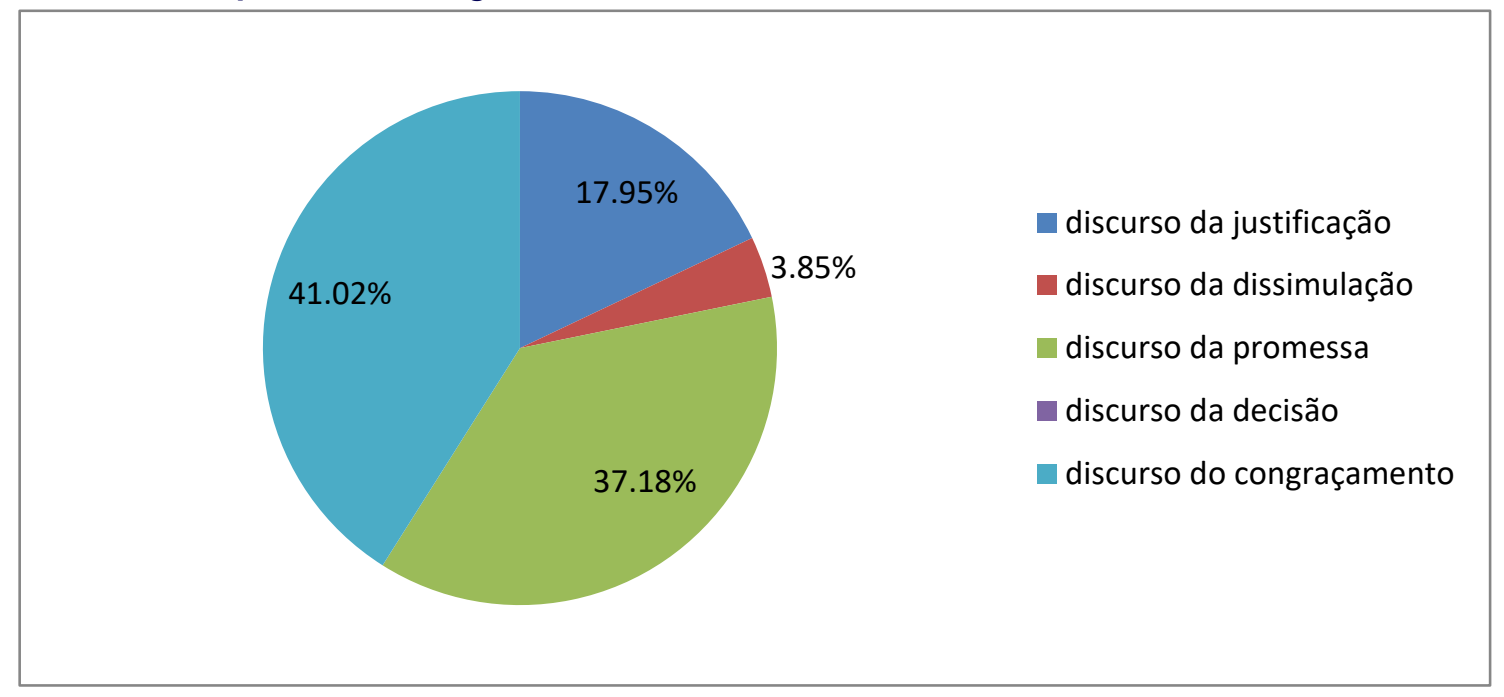

As duas estratégias discursivas com maior frequência mobilizadas na construção do ethos de credibilidade foram nitidamente os discursos da promessa $(37,18 \%)$ e do congraçamento (41, 02\%). Isto não se deu sem razão, pois esses dois discursos estiveram atrelados um a outro, estando o de congraçamento a serviço da promessa.

\footnotetext{
${ }^{2}$ Cada estratégia, como categoria analítica, orientou a coleta dos dados, segundo a ocorrência, na fala de cada candidato, dos discursos sob análise neste trabalho: justificação, promessa, dissimulação, congraçamento e decisão. Este último não ocorreu no debate. $\mathrm{O}$ gráfico 2 , à frente, mostrará a quantidade de ocorrências por candidato.
} 
Como? O político permitia sem tensão um espaço de fala confortável ao adversário, propondo um tópico favorável a ambos. O desdobramento era que eles podiam se utilizar do discurso da promessa e desenvolver seu programa de governo. Já que os temas abordados nessas ocasiões, em geral, não eram conflitantes, operava-se o discurso do congraçamento, em apoio mútuo.

A estratégia da justificação $(17,95 \%)$ foi também um importante recurso na formulação do ethos político de credibilidade. $\mathrm{O}$ fato de essa estratégia estar vinculada à defesa da imagem de si fez com que ela se intensificasse necessariamente na fala de um político, mas não ocorresse na de outro. Então, em um debate, a medida da crítica é muito relativa. São feitas se necessário e direcionadas conforme a dinâmica das intenções de voto e/ou oposição partidária.

Também a estratégia da dissimulação $(3,85 \%)$ se fez presente na defesa contra ataques do político oponente. Ressalte-se que sua ocorrência aqui esteve vinculada a acusações hipotéticas, sem a força do fato, da comprovação. Talvez seja compreensível, então, o não investimento do político alvejado em arrolar justificativas contrárias.

O emprego desses discursos variou entre os políticos. O gráfico 2 , a seguir, traz a relação "tipos de estratégia" vs. "candidato":

\section{Gráfico 2 - Tipos de estratégia por candidato}

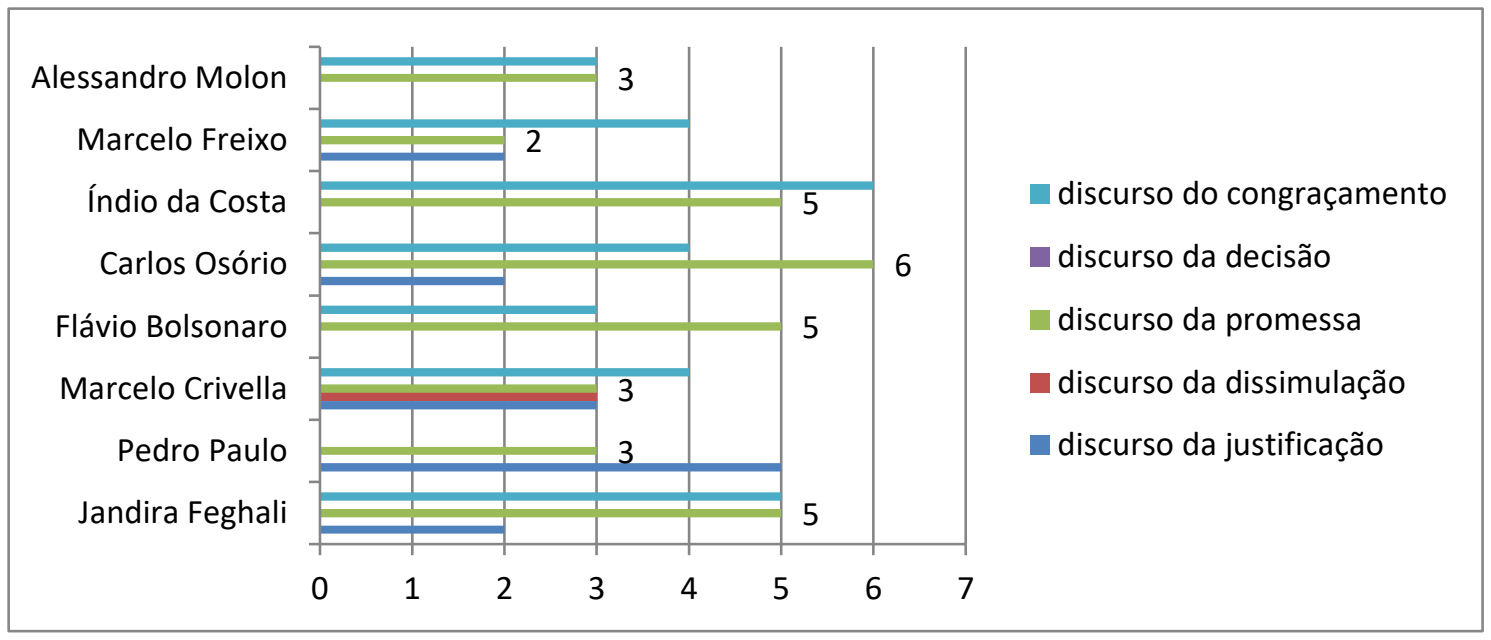

Índio da Costa, Alessandro Molon e Flávio Bolsonaro foram os candidatos que se utilizaram apenas do discurso da promessa e do congraçamento. As críticas e acusações realizadas por esses candidatos não foram frontais, face a face. Elas se dirigiram a Pedro Paulo/ Eduardo Paes, e aconteceram em parceria com outros candidatos. A abordagem de temas polêmicos ou claramente contrários ao programa de algum concorrente também foi desenvolvida fora da esfera de uma possível resposta, ou seja, operacionalizada pela estratégia do congraçamento.

$\mathrm{Na}$ fala de Marcelo Freixo, predominou a análise dos problemas da cidade, o autoelogio ao seu programa e a crítica ao candidato do PMDB, Pedro Paulo. Quase não adotou o discurso canônico da promessa e precisou pouco lançar mão da justificação, apenas duas vezes. 
Também Jandira Feghali e Carlos Osório utilizaram duas vezes o discurso/estratégia da justificativa. Jandira foi a única candidata que atingiu a marca superior a quatro vezes no uso nas estratégias de promessa e congraçamento; os demais candidatos usaram expressivamente uma ou outra. Em Jandira, então, notou-se maior equilíbrio na vinculação dessas duas estratégias.

Por fim, Marcelo Crivella foi o candidato que variou mais equilibradamente o uso dos discursos estratégicos. Ele foi o único, por exemplo, a adotar o emprego do discurso da dissimulação. Talvez, por liderar as pesquisas de intenção de voto, o confronto excessivo não fosse a principal estratégia. Atacar, mas não se mostrar desequilibrado pela acusação do oponente pode-se dizer ter sido também uma estratégia de construção de ethos de equilibrado, de calmo, imagem ideal valorizada na sociedade.

\section{CONCLUSÃO}

Neste trabalho nos dedicamos ao estudo das estratégias discursivas mobilizadas pelos candidatos ao cargo de prefeito da Cidade do Rio de Janeiro. O debate político foi promovido pela TV Globo em setembro de 2016, às vésperas das eleições.

A partir da observação e análise dos dados, pudemos delinear um quadro que desvela um pouco do jogo de intencionalidades subjacentes à superfície do debate tal como é visto pelo grande público.

Os dados nos levaram à identificação de uma estratégia ainda não descrita por Charaudeau: o discurso do congraçamento, de importância fundamental para a compreensão da dinâmica deste e de outros debates. Este discurso esteve articulado a outro, o da promessa. São as ligações íntimas entre esses dois um ponto importante de nossas reflexões.

Alguns políticos, em tese competidores, articularam-se na preparação de uma zona ausente de ataques, propícia à defesa de si e do seu programa de governo. O discurso do congraçamento (discurso do acordo, da combinação, da camaradagem) foi operacionalizado por meio de perguntas direcionadas estrategicamente a um candidato que possuía propostas de governo semelhantes. Ainda, as falas apoiavam-se mutuamente por indicadores como, "concordo", "você tem razão" num acordo em que cada um dispunha de espaço para elaboração do seu ethos de credibilidade, uma vez que naqueles minutos interrompiam-se as tensões naturais da situação de comunicação do debate político.

Longe de dizer que não adotaram a estratégia do congraçamento, à exceção de Pedro Paulo, já fragilizado política e moralmente (portanto, diga-se no campo político, alguém de quem se dissociar), as tensões de fato aguardadas ficaram a cargo, principalmente, daqueles que lideravam as intenções de voto: Marcello Crivella, Marcelo Freixo e Pedro Paulo. Este último, representando a legenda no poder (PMDB), era, dessa forma, alvo "natural" dos demais candidatos, para os quais também a elaboração da imagem de si passava pela descredibilização da imagem do outro, procedimento tradicional no discurso político. Isto levou esses três candidatos a protagonizarem momentos de tensão em que necessitavam do discurso da justificação como recurso de sua defesa ou da dissimulação, no caso de Crivella. Já que este era líder nas pesquisas, ignorar a fala do adversário (dissimulação) era estrategicamente conveniente, sobretudo se as acusações consistissem em hipóteses fortes. 
Os discursos da justificação, da promessa, da dissimulação e do congraçamento engendraram, de modo central, a elaboração de uma imagem de homem e político confiável, digno de fé. Por fim, o tão almejado ethos de credibilidade política, em situações conflituosas como a do debate político, é sempre instável, devendo o político gerenciar a sua fala e a do outro sobre si. Nesse sentido, as estratégias exerceram bem seu papel.

\section{REFERÊNCIAS}

AMOSSY, R. O ethos na intersecção das disciplinas: retórica, pragmática, sociologia dos campos. In: (Org.). Imagens de si no discurso: a construção do ethos. São Paulo: Contexto, 2005.

ARISTÓTELES. Retórica. 2. ed. Lisboa: Imprensa Nacional-Casa da Moeda, 2005.

CHARAUDEAU, P. Identité sociale et identité discursive, le fondement de la compétence communicationnelle. Gragoatá, Niterói, n. 21, p. 339-354, jul./dez. 2006a.

O discurso político. In: EMEDIATO, W; MACHADO, I.L; MENEZES, W (Orgs.). Análise do discurso: gêneros, comunicação e sociedade. Programa de Pós-graduação em Estudos linguísticos. Faculdade de Letras da UFMG, 2006 b.

Linguagem e discurso: modos de organização. 2. ed. São Paulo: Contexto, 2010.

Discurso Político. 2. ed. São Paulo: Contexto, 2011.

A conquista da opinião pública: como o discurso manipula as escolhas políticas. São Paulo: Contexto, 2016.

CHARAUDEAU P; MAINGUENEAU, D. Dicionário de Análise do discurso. São Paulo: Contexto, 2004.

EGGS. E. Ethos aristotélico, convicção e pragmática moderna. In: AMOSSY, R. Imagens de si no discurso: a construção do ethos. São Paulo, Contexto, 2005.

MAINGUENEAU, D. Análise de textos de comunicação. 6. ed. São Paulo: Cortez, 2011.

Ethos, cenografia, incorporação. In: AMOSSY, R. Imagens de si no discurso: a construção do ethos. São Paulo, Contexto, 2005.

PERELMAN, C.; OLBRECHTS-TYTECA, L. Tratado da argumentação: A nova retórica. São Paulo: Martins Fontes, 1999.

Recebido em: 30/04/17. Aprovado em: 11/10/17.

Title: Discursive strategies for an ethos of credibility in political debate

Author: Wagner Alexandre dos Santos Costa

Abstract: The political scene depends on a relation between social identity and discursive identity. In diverse situations of his/her activity, the politician must build an ethos of credibility, since he/she is always involved in a discursive struggle. In this article, we make a qualitative analysis of the construction of the favorable image of itself through discursive strategies - such as justification, dissimulation and promise - in the televised political debate of the 2016 elections to the position of Mayor of the City of Rio de Janeiro. The confirmed hypothesis is that leading politicians in opinion polls need to articulate these strategies more intensively, especially that of justification. In addition, the data led to the identification of another discursive strategy (ingratiation), and the analysis to the conclusion that the candidates construct spaces of agreement only apprehensible by a close observation. The theoretical contribution of the study is the Semiolinguistic Theory by Charaudeau (2006a, 2006b, 2010, 2011 and 2016).

Keywords: Political speech. Discursive ethos. TV debate. 
Titulo: Estrategias discursivas para un ethos de credibilidad en el debate político Autor: Wagner Alexandre dos Santos Costa

Resumen: La escena politica depende de la relación entre la identidad social y la identidad discursiva. En varias situaciones de su actividad, el político debe construir un ethos de credibilidad, ya que está siempre involucrado en una lucha discursiva. En este artículo se hace un análisis cualitativo de la construcción de la imagen favorable de si por medio de estrategias discursivas - como justificación, disimulación y promesa - en debate político televisivo de las elecciones de 2016 al cargo de Alcalde de la Ciudad de Río de Janeiro. La hipótesis confirmada es que los políticos líderes en las encuestas de opinión necesitaban articular más intensamente esas estrategias, sobre todo la de la justificación. Además, los datos llevaron a la identificación de otra estrategia discursiva (congración), y el análisis a la conclusión de que los candidatos construyen espacios de acuerdo sólo aprehensibles por una observación atenta. El aporte teórico del estudio es la Teoría Semiolingüística de Charaudeau (2006a, 2006b, 2010, 2011 y 2016).

Palabras clave: Discurso político. Ethos discursivo. Debate televisivo.

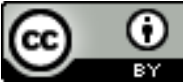

Este texto está licenciado com uma Licença Creative Commons Atribuição 4.0 Internacional. 